\title{
Potential of energy saving on transport
}

\author{
Olga Gamayunova ${ }^{1, *}$, and Roman Golov ${ }^{2}$ \\ ${ }^{1}$ Peter the Great St. Petersburg Polytechnic University, Polytechnicheskaya, 29, \\ St.Petersburg, 195251, Russia \\ ${ }^{2}$ Moscow Aviation Institute, Volokolamskoe highway, 4, Moscow, 125993, Russia
}

\begin{abstract}
The transport system of the Russian Federation includes not only railway, automobile, air, sea and river transport, but also main gas and oil pipelines. Given the volume and variety of modes of transport, the introduction of measures to improve energy efficiency in the transport sector will save significant amounts of fuel and energy resources. In the light of the annual increase in energy consumption, the degree of negative impact on the environment and the amount of emissions of harmful substances, energy saving issues in transport make this issue even more important. The article describes the dynamics of the Russian car market for the previous year, shows the key ways to improve energy efficiency and energy saving in road transport.
\end{abstract}

\section{Introduction}

The transport sector is closely connected with almost all branches of production and the social sphere, that's why transport development trends closely follow the general dynamics of economic development. For all the variety of conditions and specifics of the work of various sub-sectors of the transport sector, the efficiency of using fuel and energy resources in it is rather low.

The trend of recent years is the constant increase in fuel consumption by road. This is due to an increase in the number of cars per person.

In all analytical studies examining the prospects of the automobile market in Rus-sia, the provision of the population with light vehicles, expressed in the number of cars per 1000 people, is indicated as the most striking illustrative indicator (see Fig.1). Since this indicator is really lower for Russia than in most developed countries, it is concluded that the market potential is very large.

If we consider the dynamics of the Russian auto market as a whole, then we can cite the following figures.

In 2018, new car sales in Russia grew by $12.8 \%$ compared to 2017. Both segments (mass and premium) also showed growth $(+13.9 \%$ and $+7.4 \%$, respectively). Sales of mass-produced cars in 2018 reached 1,572,246 units, which is $91.2 \%$ of the total sales.

\footnotetext{
* Corresponding author: gamayunova_os@ spbstu.ru
} 


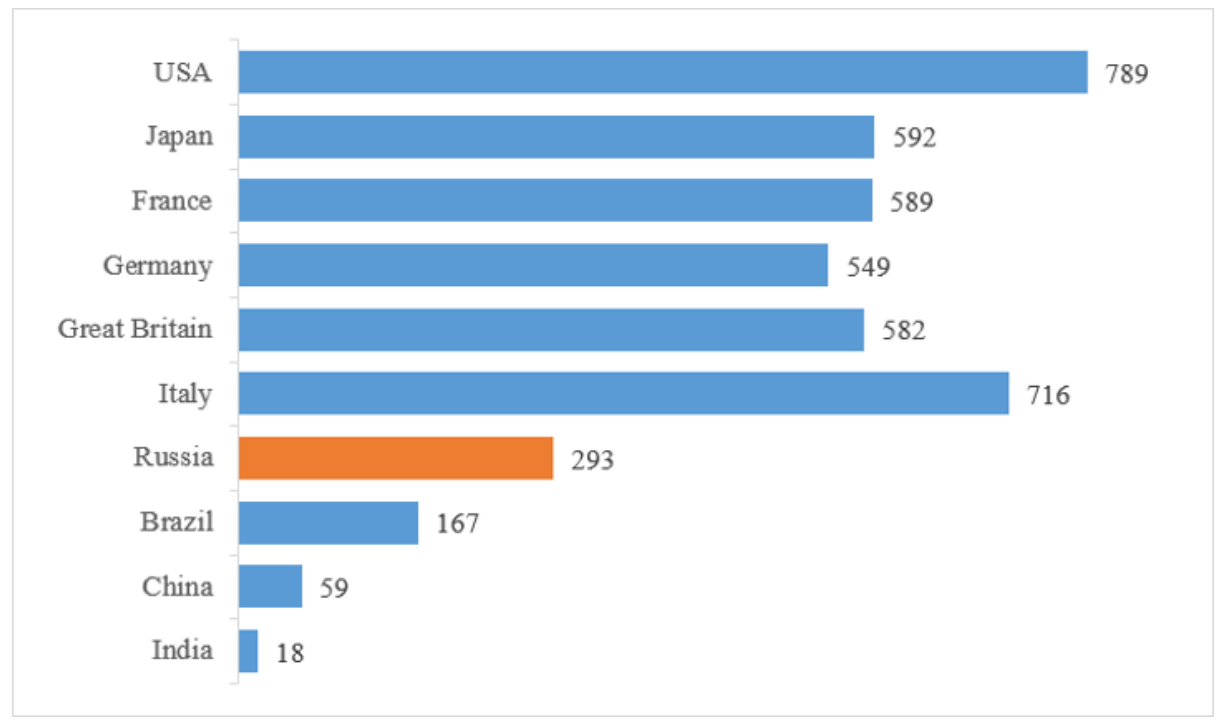

Fig. 1. Provision of population with cars by country (number of cars per 1000 people)

It is worth noting that among the TOP-25 brands-leaders 18 showed a positive trend. Zotye showed the greatest growth - sales of cars of the Chinese brand grew almost 3 times. Japanese Honda $(+110 \%)$ and Mitsubishi $(+86.6 \%)$ also showed high dynamics. Of the seven brands that showed negative dynamics in the mass seg-ment, the largest drop was recorded in the Uzbek Ravon (-65.6\%).

Sales of premium segment cars last year increased by $7.4 \%$ and amounted to 151,655 units (share $-8.8 \%$ ). Most representatives of this segment are in the black (10 out of 14 brands). The largest sales growth was observed at Genesis, whose sales grew by $77.6 \%$. Other brands show more "modest" growth rates - from $+2.6 \%$ (Lex-us) to $+47.5 \%$ (MINI). The largest drop among premium brands for 2018 was ob-served in Smart (- 26.2\%).

The increase in the number of cars has led to a decrease in the energy efficiency of passenger transportation.

The following technologies can be noted as key ways to increase energy efficiency in road transport: reducing the weight of the car, using alternative types of fuel, in-creasing the use of polymeric materials (plastics) in cars, using "green" tires, etc.

\section{Car weight reduction}

The need to reduce the weight of the car appeared during the first oil crisis of 1973 (which provoked a strong increase in fuel prices in developed countries). By reducing the mass of the car, the developers are trying to achieve increased mileage per unit of fuel consumed. According to estimates by the US National Academy of Sciences, every $5 \%$ reduction in vehicle weight leads to a gain in mileage of $3-4 \%$.

Studies by vehicle manufacturers show that reducing the weight of cars and trucks due to the increasing use of polymer materials can achieve great savings. However, until recently, the widespread use of polymeric materials in mechanical engineering was hindered by low strength and heat resistance, compared to grade steels. The tran-sition to composite materials, such as carbon plastics, helped to solve these problems.

A characteristic feature of cars of domestic brands is a rather low proportion of polymer products in the total mass (see Fig. 2). 


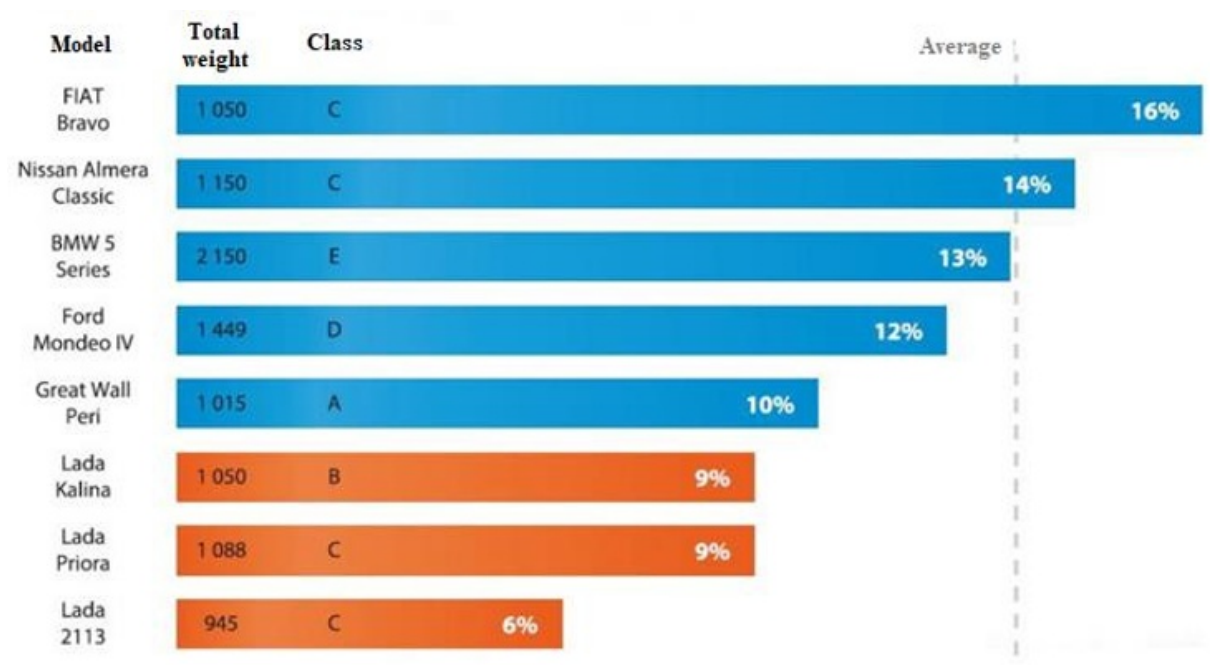

Fig. 2. The weight content of polymers in different car models

Based on this correlation and the conservative forecast of the pace of development of the Russian economy, prepared by the Ministry of Economic Development, the provision of the population of Russia with cars by 2020 could grow to 315 units per 1000 people. Based on this, we can estimate the size of the fleet of cars in Russia in 2020 at 45 million units, which is $22 \%$, or 7 million units, higher than the level of 2013. It is clear that this niche is closed by the current volume of car production in Russia for three years.

\section{$3 \quad$ Alternative fuel}

Energy saving in transport is directly related to the type of fuel used. In particular, the use of liquefied natural gas. And this affects both the environmental component and the cost of transportation.

The overall energy efficiency (taking into account the fact that the average economic effect of converting 1 car to gas is about 0.3 toe) when transferring about $30 \%$ (about 9.3 million cars) of a Russian passenger car fleet to the use of liquefied hydrocarbon gas as a motor fuel can be estimated at 2.7 million toe.

According to the International Energy Agency (IEA), the production of gasoline and diesel fuel in the world consumes 1,514.5 million tons of oil per year. Applying new technologies that increase the energy efficiency of the car, we can achieve significant savings in traditional fuel used by vehicles.

The cost of oil and gas resources is growing, stocks of cheap oil are approaching exhaustion, environmental pollution by products contained in gasoline exhaust is becoming increasingly widespread, and the growth rate of the car fleet remains at a high level. Therefore, the problem of switching to alternative types of motor fuels is becoming increasingly important. From the list of technologies considered as possible solutions to this problem, such as methanol, biogas, electric cars, synthetic gasoline, today we can talk about two practically mastered directions - these are liquefied hydrocarbon gases and liquefied natural gas.

Alternative fuels currently used are biofuels (see Table 1), hydrogen and electricity. Gas stations where you can refuel the car with an alternative type of fuel are already working (see Fig. 3). 
Table 1. Classification of biofuels

\begin{tabular}{|c|c|c|}
\hline Biofuel generation & Raw materials & Biofuel Examples \\
\hline First generation & $\begin{array}{l}\text { Biological raw materials: } \\
\text { sugar, starch, vegetable oil } \\
\text { and animal fat }\end{array}$ & $\begin{array}{l}\text { Bioethanol, biodiesel (contain an oxygen atom } \\
\text { in the molecule) }\end{array}$ \\
\hline Second generation & $\begin{array}{l}\text { Non-food raw materials } \\
\text { (waste) }\end{array}$ & $\begin{array}{l}\text { Bioethanol, biodiesel. Fischer-Tropsch biodiesel } \\
\text { (does not contain an oxygen atom in the } \\
\text { molecule) }\end{array}$ \\
\hline Third generation & Seaweed & Bioethanol, biohydrogen, biogas \\
\hline
\end{tabular}

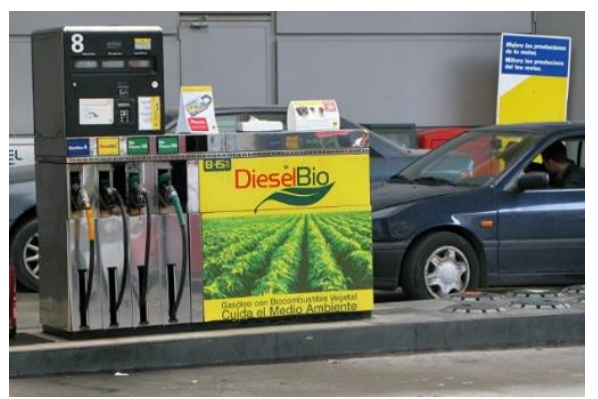

a)

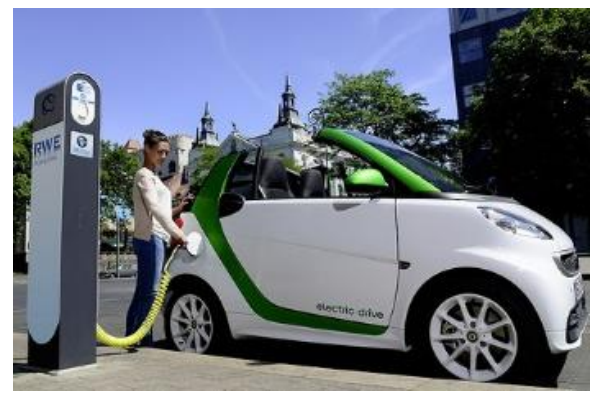

b)

Fig. 3. Alternative fuel stations: a - biofuel gas station, b - electric vehicle refueling

\section{4 “Green” tires}

The popularity of tires with reduced rolling resistance began with the introduction of the first generation Michelin Energy Saver ten years ago, when Michelin proved that such tires do not necessary have to constantly slip and be hard as stone. According to Michelin, the use of "green" tires, with an average annual mileage of about 20 thousand $\mathrm{km}$, reduces annual fuel consumption by 40 liters. Considering that the Russian passenger car fleet currently exceeds 30 million cars, the use of green tires when equipping this car fleet will save about 1 million tons of fuel resources annually.

The production of the "green" tire provides for the improvement of environmental performance and reduction of rolling energy losses during exploitation. This, in turn, reduces the vehicle's fuel consumption and exhaust emissions into the surrounding atmosphere.

Rolling resistance is the force opposed to movement during tire rotation. Tires with low resistance will roll easier, and with them fuel consumption will be lower than tires with high rolling resistance. According to the American Transportation Research Board (TRB), a $10 \%$ reduction in rolling resistance reduces fuel consumption by $1.5 \%$.

Michael Sivak, a professor of the University of Michigan Transportation Research Institute (UMTRI), measured the rolling resistance of 63 tires of the same size at the same pressure and load to determine the annual fuel consumption for an average American driver. According to Sivak's calculations, the fuel consumption of an "average" car will thus vary from 10.5 to 11.36 liters per $100 \mathrm{~km}$. Having obtained this data, the professor came to the conclusion that tires with low rolling resistance can reduce fuel consumption in a year from 547 to 505 gallons (from 2,071 to 1,912 liters). Given the average price of gasoline, for example, in Russia for a year, savings will be more than 100 U.S. Dollar, for the United States - more than 120 U.S. Dollar. 


\section{Conclusions}

In transport, the demand for the most high-quality and expensive energy carriers (motor fuel and electricity) is increasing every year. Therefore, the energy conservation policy on transport is becoming increasingly relevant.

In our country, there is a huge reserve in the field of energy conservation. As the figures show, we can reduce almost half of the current energy consumption due to energy saving. Unleashing the potential for energy conservation depends on specific energy-saving measures.

Studies by vehicle manufacturers show that reducing the weight of cars and trucks due to the increasing use of polymer materials can achieve great savings. If earlier weight loss was achieved through the use of expensive magnesium and aluminum, now composite materials have replaced them. To date, almost all major automakers have embarked on a reduction in vehicle weight. And first of all it concerns the carbody. Its lightweight design means the possibility of using a more compact brake system and engine, a smaller fuel tank and so on. Reducing the weight of the carbody structure goes in several directions: optimization of the carbody structure, the use of light materials and the introduction of new production processes. The latter include, for example, laser welding, friction welding or methods for manufacturing parts by hot stamping or hydroforming.

The use of green tires reduce rolling resistance, improves grip, and saves up to $10 \%$ of fuel. Green tires are still 5-10\% more expensive than their regular counterparts, but giving $5 \%$ fuel savings, reducing carbon dioxide emissions, and providing better wet grip, they become competitive.

One of the main measures to save energy and increase energy efficiency in the operation of automobile transport is the replacement of petroleum motor fuels with alternative fuels, primarily liquefied natural gas. The most important plus is that gas is almost three times cheaper than gasoline and diesel. Another plus is less environmental damage. The use of natural gas instead of petroleum fuels allows reducing the emission of carbon monoxide by 8 times, nitrogen oxides by 2 times, hydrocarbons by 3 times, and soot emissions are completely eliminated. The use of gaseous fuels eliminates unauthorized interference with the vehicle's power system and the use of inappropriate motor fuels.

All the tips above show that starting to save fuel is not as difficult as it seems at first glance.

\section{References}

1. N. Sevryugina, M. Stepanov, Magazine of Civil Engineering 7 (75), 23-36, (2017).

2. The dynamics of the Russian car market in 2018, https://www.autostat.ru/infographics/37409/, last accessed 2019/08/22.

3. S.V. Myakishev, Transport: science, equipment, management, Vol. 7, 42-45, (2017).

4. Yu. Lazarev, Technical and technological problems of service 1 (43), 61-65, (2018).

5. O. Poddaeva, A. Kubenin, D. Gribach, Advances in Intelligent Systems and Computing, Vol. 692, 490-497, (2018).

6. S. Vysotskiy, N. Stolyarova, S. Kuzmina, Energosberezheniye 9, 6-9, (2012).

7. M. Telegina, A. Barabash, E. Naumova, O. Zhuvak, Yu. Lazarev, Construction of Unique Buildings and Structures, Vol. 11 (62), 71-82, (2017).

8. A. Tsal, N. Ermoshin, P. Sereda, Inzhenernyy vestnik Dona 1 (48), 139, (2018).

9. Yu. Lazarev, N. Ermoshin, Technical and technological problems of service, Vol. 1 (39), 58-62, (2017).

10. A. Hnatov, S. Arhun, S. Ponikarovska, International Journal of Automotive and Mechanical Engineering 4 (14), 4649-4664, (2017). 